\title{
Profil lesi mulut pada kelompok lanjut usia di Panti Sosial Tresna Wreda Senjarawi Bandung
}

\author{
Nanan Nur'aeny* dan Kartika Indah Sari** \\ *Departemen IImu Penyakit Mulut, Fakultas Kedokteran Gigi, Universitas Padjadjaran, Bandung, Jawa Barat, Indonesia \\ ${ }^{* *}$ Departemen Biologi Oral, Fakultas Kedokteran Gigi, Universitas Padjadjaran, Bandung, Jawa Barat, Indonesia \\ *JI Sekeloa Selatan No 1 Bandung, Jawa Barat, Indonesia; e-mail: nanan.nuraeny@fkg.unpad.ac.id
}

Submisi: 26 April 2016; Penerimaan: 11 Mei 2016

\begin{abstract}
ABSTRAK
Tujuan dari penelitian ini adalah untuk mengetahui profil lesi mulut pada kelompok lanjut usia di panti sosial tresna wreda Senjarawi Bandung. Penelitian dilakukan pada Panti Sosial Tresna Wreda (PSTW) Senjarawi di kota Bandung, dengan metode cross-sectional. Sampel penelitian dipilih sesuai kriteria inklusi meliputi sehat fisik dan mampu berkomunikasi dengan baik, usia minimal 60 tahun, dan mandiri. Hasil pemeriksaan pada 20 sampel menunjukkan adanya lesi mulut seperti coated tongue, fissured tongue, lesi ulserasi, geographic tongue, fordyce granule, dan lesi traumatik. Jumlah terbanyak yaitu 11 orang (55\%) mengalami coated tongue. Hasil pemeriksaan gigi ditemukan sebanyak 18 sampel $(90 \%)$ mengalami kehilangan beberapa gigi. Coated tongue banyak ditemukan terkait dengan kondisi gigi yang dialami, kebiasaan makan, faktor fisiologis, dan kondisi sistemik, sedangkan beberapa lesi mulut lainnya terjadi sesuai dengan penambahan usia. Lesi ulserasi yang ditemukan mirip dengan lesi recurrent aphthous stomatitis (RAS), tetapi pada usia lanjut ulserasi mulut lebih sering dipengaruhi oleh kondisi sistemik dan pengobatannya sehingga diagnosis ulser lebih sebagai suatu RAS-like. Coated tongue sebagai lesi mulut yang paling banyak ditemukan karena dipengaruhi oleh proses degeneratif, status kebersihan mulut, pola makan, dan tempat tinggal. Kesehatan gigi dan mulut lansia merupakan hal yang perlu mendapat perhatian termasuk dari dokter gigi sehingga diharapkan dapat tercapai kualitas hidup lansia yang baik.
\end{abstract}

Kata kunci: lesi mulut, lanjut usia

ABSTRACT: Oral lesions profile in elderly group at Panti Sosial Tresna Wreda Senjarawi Bandung. The aim of the paper is to determine the profile of oral lesions in elderly. The study was conducted on Panti Sosial Tresna Wreda (PSTW) Senjarawi in Bandung, with a cross-sectional method. Samples were selected according the inclusion criteria include physically healthy, be able to communicate well, at least 60 years of age, and independent. The examination of 20 samples showed oral lesions such as coated tongue, fissured tongue, ulcerated lesions, geographic tongue, fordyce granules, and traumatic lesions. Dental examination showed that among 18 samples (90\%) had lost several teeth. Coated tongue was found associated with dental conditions, eating habits, physiological factors, and systemic conditions, whereas some other oral lesions occur in accordance with the ages. Ulcerated lesions were found similar to lesions of recurrent aphthous stomatitis (RAS), but in the elderly oral ulceration more often influenced by systemic condition and treatment so that the diagnosis of ulcers is more as a RAS-like. Coated tongue is the most oral lesion found which influenced by the degenerative processes, oral hygiene status, diet, and residence. The oral health of elderly is a necessary part to get attention, including from the dentist in order to achieve a good quality of life.

Keywords: oral lesion, elderly

\section{PENDAHULUAN}

Berdasarkan data dari Badan Pusat Statistik, jumlah penduduk lanjut usia (lansia) di Indonesia setiap tahunnya selalu mengalami kenaikan. Sejak tahun 2000, persentase penduduk lansia lebih dari $7 \%$ yang berarti Indonesia mulai masuk ke dalam kelompok negara berstruktur tua (ageing population). Hal ini menunjukkan tingginya ratarata usia harapan hidup (UHH) di Indonesia. ${ }^{1}$ Saat memasuki usia lanjut, manusia mengalami proses penurunan fungsi tubuh (penuaan/degeneratif), tetapi kualitas hidup tetap perlu dijaga, salah satu usahanya dengan menjaga kesehatan tubuh termasuk kesehatan rongga mulut.

Kondisi gigi pada lansia dapat mengalami perubahan, diantaranya gigi karies, gigi goyang sampai kehilangan gigi. Kondisi mukosa mulut lansia juga dapat mengalami suatu kelainan. Beberapa kondisi berikut dilaporkan sering ditemukan pada lansia, yaitu denture stomatitis, angular 
stomatitis, karsinoma, herpes zoster, post-herpetic neuralgia, liken planus, mucous membrane pemphigoid, lesi premalignan, sindrom Sjögren, dan trigeminal neuralgia. ${ }^{2}$ Kondisi lansia pada suatu komunitas seperti Panti Sosial menjadi tempat yang tepat untuk mengetahui berbagai variasi kondisi kesehatan lansia termasuk kesehatan mulutnya. Bervariasinya faktor yang mendukung kondisi kesehatan mulut lansia diantaranya faktor nutrisi, penyakit degeneratif dan efek obatnya dapat mempengaruhi munculnya lesi pada mukosa mulut. Data hasil mapping untuk profil lesi mulut belum banyak diteliti dan hasil epidemiologi khusus untuk lesi mulut masih belum mencakup populasi yang luas, sehingga peneliti bermaksud untuk melakukan penelitian ini terhadap kelompok lansia di Panti Sosial Tresna Wreda (PSTW) Senjarawi yang terpilih secara random sampling dari lima PSTW yang ada di kota Bandung. Hasil pemeriksaan rongga mulut menunjukkan adanya lesi mulut seperti coated tongue, fissured tongue, lesi ulserasi, geographic tongue, fordyce granule, dan lesi traumatik. Profil lesi mulut yang ditunjukkan dari penelitian ini menjadi gambaran lesi mulut yang dapat ditemukan pada populasi subjek lansia.

\section{METODE PENELITIAN}

Penelitian dilakukan setelah mendapat ljin etik penelitian yang dikeluarkan oleh komite etik Fakultas Kedokteran Universitas Padjadjaran. Tempat dan waktu penelitian di Panti Sosial Tresna Wreda (PSTW) Senjarawi di Jalan Jeruk no.7 Bandung, pada Bulan September 2015 sampai dengan Januari 2016. Penelitian ini merupakan penelitian deskriptif menggunakan metode crosssectional. Populasi penelitian ini adalah seluruh penghuni PSTW di Kota Bandung, sedangkan populasi terjangkaunya adalah seluruh penghuni PSTW Senjarawi. PSTW Senjarawi terpilih secara random sampling dari lima PSTW yang ada di kota Bandung. Unit sampling ditentukan dari penghuni PSTW Senjarawi yang memenuhi kriteria inklusi dan kriteria eksklusi. Kriteria inklusi meliputi sehat fisik dan mampu berkomunikasi dengan baik, berusia $\geq 60$ tahun, dan mandiri, mampu melakukan aktivitas dasar secara mandiri. Kriteria eksklusi meliputi tidak bersedianya subjek untuk mengikuti penelitian sampai selesai. Penetapan sampel yang digunakan dalam penelitian ini menggunakan metode random sampling, teknik sampling ini dipilih karena di dalam pengambilan sampelnya, peneliti mengacak subjek di dalam populasi sehingga semua subjek dalam populasi dianggap sama. Rumus besar sampel penelitian ini adalah: ${ }^{3}$

$$
\begin{aligned}
\mathrm{n} 1=\mathrm{n} 2 & =2 \times\left(\frac{\left(z_{1-\alpha / 2}+z_{1-\beta}\right) s}{x_{1}-x_{2}}\right)^{2}=2 \times\left(\frac{(1.96+0.84) 11.91}{10.54}\right)^{2} \\
& =20.02 \sim 20
\end{aligned}
$$

$Z_{\alpha}=$ deviat baku alfa, $\alpha=.05, Z_{.05}=1.96$ (two-sided)

$Z \beta=$ deviat baku beta, $\beta=.2, Z_{.2}=0.84$

$\mathrm{x}_{1}-\mathrm{x}_{2}=$ significant mean difference $=10,54$

Variabel dalam penelitian meliputi umur, jenis kelamin, kondisi atau riwayat penyakit sistemik, kondisi gigi dan lesi mulutnya. Instrumen penelitian adalah lembar penelitian berupa formulir pemeriksaan rongga mulut, lembar kuesioner, alat dasar pemeriksaan rongga mulut, dan alat tulis. Penelitian ini dilakukan dengan cara mengumpulkan seluruh subjek sesuai kriteria, kemudian subjek penelitian dikumpulkan pada ruangan tertentu. Peneliti menjelaskan maksud dan tujuan dari dilakukannya penelitian, dan manfaat yang diperoleh dari hasil penelitian. Subjek penelitian yang bersedia berpartisipasi pada penelitian, harus menandatangi persetujuan penelitian (informed consent), kemudian dilakukan wawancara, dan pemeriksaan rongga mulut meliputi jaringan keras dan lunak mulut. Seluruh data dicatat dan dikelompokkan kemudian diolah untuk disajikan dalam tabel dan dilakukan pembahasan. Data yang sudah dikumpulkan dianalisis dengan menggunakan Microsoft excel 2010 untuk mengetahui kondisi mukosa mulut.

\section{HASIL PENELITIAN}

Seluruh subjek yang terkumpul berjumlah 20 orang, yaitu sebanyak 7 orang laki-laki dan 13 orang wanita, dengan usia terbanyak dalam rentang 70-80 tahun (Tabel 1). Data kondisi sistemik dari 20 subjek menunjukkan pasien terbanyak dengan presesentasi $63,2 \%$ adalah dengan riwayat hipertensi (Tabel 2). 
Tabel 1. Karakteristik Sampel Penelitian

\begin{tabular}{clcc}
\hline No. & \multicolumn{1}{c}{ Karakteristik } & Jumlah & Persentase (\%) \\
\hline 1 & Jenis Kelamin & & \\
& Pria & 7 & 35 \\
2 & Wanita & 13 & 65 \\
& Usia & & \\
& 60-70 tahun & 3 & 15 \\
& 70-80 tahun & 15 & 75 \\
& 80-90 tahun & 1 & 5 \\
& $90-100$ tahun & 1 & 5 \\
\hline
\end{tabular}

Tabel 2. Penyakit yang diderita (\%)

\begin{tabular}{lr}
\hline Hipertensi & 63.2 \\
Penyakit metabolik & 10.5 \\
Penyakit muskuloskeletal & 21.1 \\
Lain-lain & 5.3 \\
\hline
\end{tabular}

Hasil penelitian didapatkan hasil terbanyak untuk kondisi gigi dan jaringan lunak mulut yaitu 18 orang (90\%) mengalami kehilangan beberapa gigi, dan 11 orang (55\%) mengalami coated tongue (Tabel 3). Gambaran coated tongue terlihat pada dorsum lidah sebagai lapisan putih kekuningan yang mudah dikerok tanpa meninggalkan jaringan eritem (Gambar 1). Kondisi lain yang ditemukan pada lidah adalah geographic tongue berupa daerah atrofi berwarna merah dikelilingi tepi putih dan lidah berfisur (Gambar 2 dan 3). Lesi mulut berupa fisur dan erosif akibat trauma dari gesekan dengan bagian gigi yang tajam juga ditemukan pada lidah bagian lateral (Gambar 4).
Lesi trauma selain ditemukan pada lidah, pada subjek lain, lesi trauma juga ditemukan pada mukosa bukal akibat iritasi bagian gigi yang tajam (Gambar 5.) Ulserasi juga dialami oleh dua orang subjek penelitian, salah satunya terjadi pada mukosa labial, ulser berukuran kecil $(\mathrm{d}=2 \mathrm{~mm})$ dan pada subjek lain ditemukan pada mukosa bukal dengan ukuran kecil $(d=3$ $\mathrm{mm}$ ) (Gambar 6). Kondisi variasi normal dari mukosa mulut seperti fordyce granule atau lesi berupa papul-papul kekuningan juga ditemukan pada mukosa bukal subjek penelitian ini (Gambar 7).

\section{PEMBAHASAN}

Perubahan fisiologis yang terjadi pada orang yang berusia lanjut juga terjadi dalam rongga mulut, termasuk bagian mukosa mulut mengalami pengurangan fungsi sehingga memudahkan untuk mengalami lesi mulut. Kondisi tubuh orang lanjut usia juga sering terkait dengan penyakit atau gangguan sistemik yang secara langsung maupun tidak langsung berkaitan dengan berkurangnyausaha dalam menjaga kebersihan mulut. Efek dari obat-obatan yang dikonsumsi terkait kondisi sistemik yang juga dapat menimbulkan lesi mulut. Gangguan yang terjadi mungkin tidak menimbulkan kematian tetapi berpengaruh pada kualitas hidup. ${ }^{4,5}$

Tabel 3. Karakteristik kondisi rongga mulut penghuni Panti Wreda Senjarawi

\begin{tabular}{|c|c|c|c|c|c|c|c|c|c|c|c|}
\hline \multirow[b]{2}{*}{ Karakteristik } & \multicolumn{5}{|c|}{ Gigi } & \multicolumn{6}{|c|}{ Mukosa Mulut } \\
\hline & $\mathrm{C}$ & $\mathrm{R}$ & $M(P)$ & $M(A)$ & $\mathrm{F}$ & CT & $\mathrm{FT}$ & Ulser & GT & $\mathrm{FG}$ & $\mathrm{TL}$ \\
\hline \multicolumn{12}{|l|}{ Jenis kelamin } \\
\hline Laki-laki & 3 & 5 & 7 & 2 & - & 5 & 4 & 1 & 2 & 1 & 1 \\
\hline Perempuan & 2 & 8 & 11 & 4 & 4 & 6 & 4 & 1 & - & 1 & - \\
\hline Total & 5 & 13 & 18 & 6 & 4 & 11 & 8 & 2 & 2 & 2 & 1 \\
\hline
\end{tabular}

Ket: $\mathrm{C}=$ karies, $\mathrm{R}=$ radiks, $\mathrm{M}(\mathrm{P})=$ hilang sebagian, $\mathrm{M}(\mathrm{A})=$ hilang seluruhnya

$\mathrm{CT}=$ coated tongue, $\mathrm{FT}=$ fissured tongue, $\mathrm{GT}=$ geographic tongue,

$\mathrm{FG}=$ fordyce granule, $\mathrm{TL}=$ traumatic lesion 


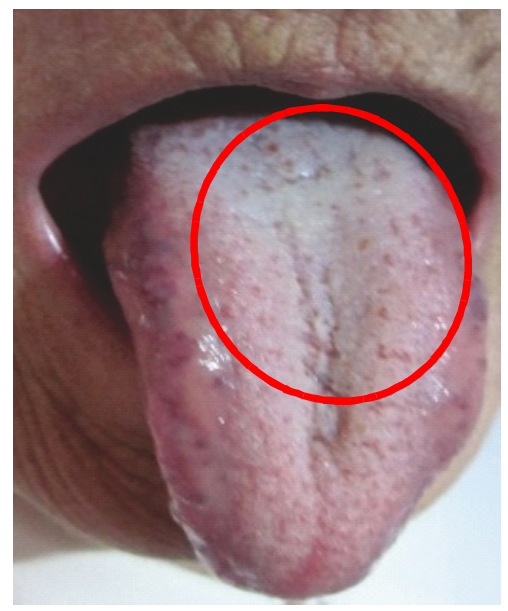

Gambar 1. Coated tongue, gambaran selaput putih pada dorsum lidah yang dapat dikerok tanpa meninggalkan jaringan eritem, pada subjek penelitian. (Dokumentasi pribadi)

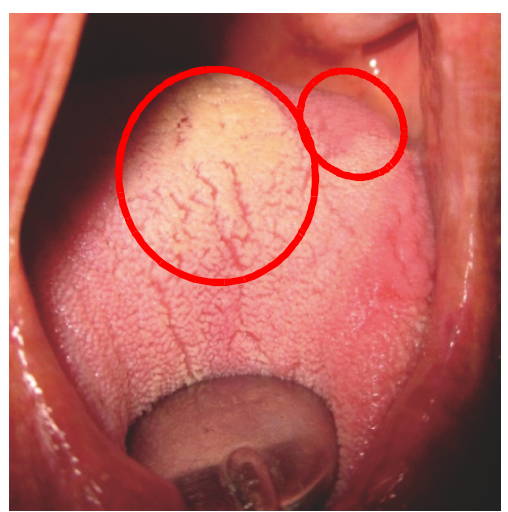

Gambar 2. Coated tongue (gambaran selaput putih pada dorsum lidah yang dapat dikerok tanpa meninggalkan jaringan eritem) disertai geographic tongue (gambaran daerah atrofi berwarna merah dikelilingi tepi putih yang sedikit meninggi) pada subjek penelitian. (Dokumentasi pribadi)

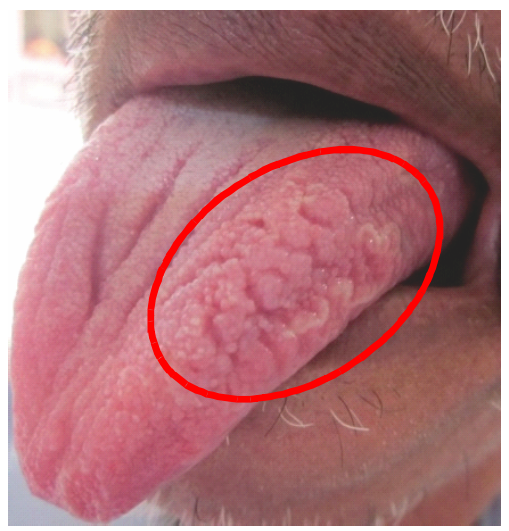

Gambar 3. Fissured tongue (gambaran celah-celah pada dorsum lidah) pada subjek penelitian. (Dokumentasi pribadi)

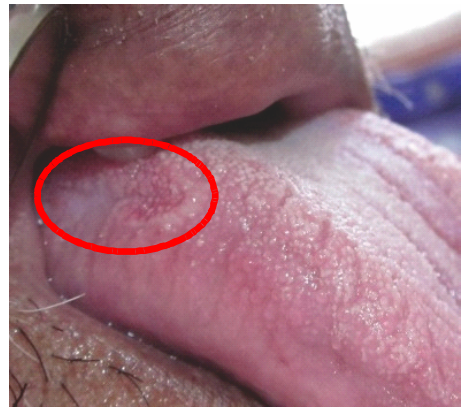

Gambar 4. Lesi traumatik berupa fisur dan erosif pada pada lateral lidah. (Dokumentasi pribadi)

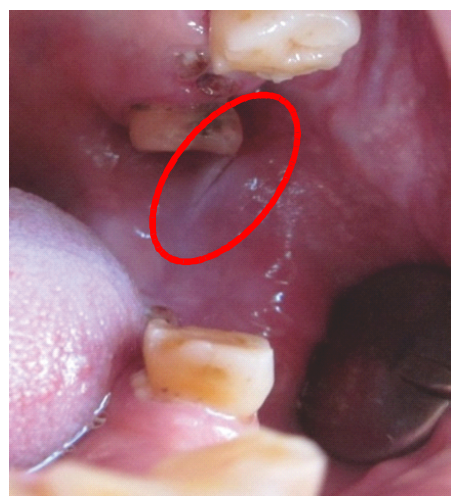

Gambar 5. Lesi traumatik pada mukosa bukal. (Dokumentasi pribadi)
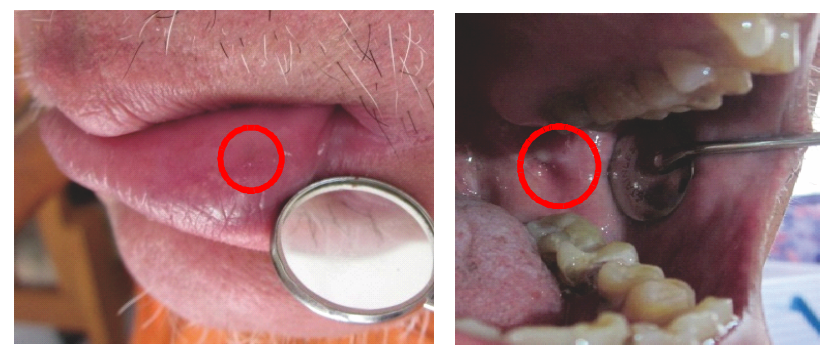

Gambar 6. Lesi ulserasi pada mukosa labial dan mukosa bukal pada subjek yang berbeda.

Foto kiri menunjukkan ulser $\mathrm{d}=2 \mathrm{~mm}$, foto kanan menunjukkan ulser $\mathrm{d}=3 \mathrm{~mm}$. (Dokumentasi pribadi)

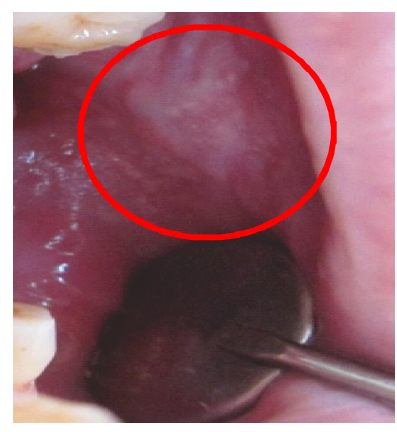

Gambar 7. Fordyce granule (lesi berupa papul-papul kekuningan) pada mukosa bukal. (Dokumentasi pribadi) 
Hasil pemeriksaan pada penelitian ini menunjukkan sebanyak 18 sampel $(90 \%)$ telah mengalami kehilangan gigi. Hal ini seperti yang telah banyak dilaporkan dalam studi epidemiologi kesehatan rongga mulut pada usia lanjut. ${ }^{5,6}$ Rongga mulut merupakan pintu masuknya infeksi mikroba, dengan manifestasi yang banyak ditemukan berupa karies dan periodontitis akibat akumulasi bakteri plak. ${ }^{5}$ Karies ditemukan sebanyak $25 \%$ dan gigi radiks sebanyak $65 \%$, hal ini menunjukkan keterlibatan infeksi bakteri yang tinggi yang didukung oleh tingkat kebersihan mulut yang buruk.

Hasil pemeriksaan mukosa mulut tidak ditemukan suatu kondisi patologis yang membahayakan seperti lesi-lesi pre kanker. Kondisi yang ditemukan berupa coated tongue, yaitu tertutupnya bagian dorsum lidah oleh suatu lapisan yang berwarna putih kekuningan/kecoklatan yang mengandung debris/sisa makanan, ataupun mikroorganisme/ flora normal mulut yang didukung oleh kebiasaan mengkonsumsi makanan lunak (karena telah mengalami kehilangan gigi), dipengaruhi pula oleh perubahan fisiologis rongga mulut, seperti berkurangnya produksi saliva ataupun akibat konsumsi obat-obatan yang secara tidak langsung berpengaruh pada produksi saliva dan ekosistem rongga mulut. ${ }^{7}$ Sebanyak dua orang subjek mengalami Diabetes Mellitus (DM) sehingga keluhan serostomia atau mulut kering juga ditemukan dan berpengaruh pada terbentuknya coated tongue. DM mempengaruhi terjadinya perubahan kelenjar saliva parotid, dan terjadinya atrofi asinar. ${ }^{7}$ Laju aliran saliva juga mengalami penurunan pada pasien $\mathrm{DM},{ }^{8}$ sehingga self cleasing dalam rongga mulut juga berkurang dan dapat mengakibatkan terjadinya coated tongue dan gigi karies. Aktivitas lidah yang juga mengalami penurunan pada usia lanjut juga mempengaruhi proses deskuamasi lidah sehingga lidah mudah mengalami coated. Kebiasaan merokok pada dua subjek penelitian juga mempengaruhi munculnya kondisi coated tongue, seperti hasil studi Gonul dkk. menyebutkan bahwa prevalensi coated tongue sebesar $64 \%$ sebagai lesi mulut yang ditemukan pada kelompok perokok. ${ }^{9}$ Efek merokok pada munculnya lesi coated tongue dipengaruhi oleh panas dan berbagai jenis toksin dari rokok, selain panasnya dapat menyebabkan mulut kering sehingga menghambat saliva dalam menyingkirkan bakteri, dan menyebabkan produksi keratin berlebih sehingga memudahkan retensi debris pada papila lidah. ${ }^{10}$

Kondisi lainnya yaitu fissured tongue, yaitu lidah yang memiliki celah pada bagian dorsum lidah. Sesuai perkembangan usia, fisur meningkat dalam jumlah, lebar, dan kedalaman. ${ }^{8}$ Hasil pemeriksaan pada penelitian ini menunjukkan sebanyak depalan orang (40\%) memiliki fisur pada permukaan dorsum lidahnya. Kondisi lidah lainnya yaitu geographic tongue yang ditemukan pada dua subjek, ditandai dengan bentuk tidak beraturan berwarna merah akibat depapilasi dan penipisan epitel/ atrofi bagian dorsum lidah, dan dikelilingi oleh bagian tepi berwarna lebih putih. ${ }^{11}$

Kondisi mukosa lainnya yang ditemukan yaitu berupa fordyce granule, yaitu kondisi akibat kelainan perkembangan yang ditandai oleh koleksi heterotrofik kelenjar sebasea pada berbagai lokasi dalam rongga mulut, seperti pada penelitian ini yang ditemukan pada dua subjek, laki dan wanita. Jumlah lesi ini meningkat secara cepat sesuai pernambahan usia. ${ }^{11}$

Manifestasi lesi mulut lainnya yaitu ulser berukuran $<1 \mathrm{~cm}$ berjumlah satu pada mukosa bukal, berbatas jelas reguler dikelilingi eritem, sebanyak dua orang mengalaminya, yaitu seorang laki-laki berusia 75 tahun, dan seorang wanita berusia 86 tahun. Sesuai gambaran klinis, lesi ini dapat disebut sebagai lesi RAS-like, yaitu lesi mirip dengan recurrent aphthous stomatitis tetapi pada usia lanjut ulserasi mulut lebih sering dipengaruhi oleh kondisi sistemik dan pengobatannya sehingga diagnosis ulser lebih sebagai suatu RAS-like.

\section{KESIMPULAN}

Profil lesi mulut pada penelitian ini memperlihatkan adanya indikasi pengaruh yang kompleks dari proses degeneratif pada lansia yang kemungkinan diakibatkan dari penurunan fungsi pengunyahan, saliva, pola makan, kondisi 
sistemik dan pengobatan yang terkait. Coated tongue sebagai lesi mulut yang paling banyak ditemukan perlu mendapat perhatian agar dapat meningkatkan kebersihan mulut lansia menjadi lebih baik. Penanganan lesi mulut lain seperti lesi ulserasi atau lesi traumatik juga penting untuk diberikan sehingga kualitas kesehatan lansia dapat lebih baik lagi.

\section{UCAPAN TERIMAKASIH}

Terima kasih kami ucapkan pada Fakultas Kedokteran Gigi Universitas Padjadjaran yang telah membantu dalam pembiayaan penelitian ini.

\section{DAFTAR PUSTAKA}

1. Kementerian Kesehatan RI. Situasi dan Analisis Lanjut Usia. [Internet.] Infodatin-Pusat Data dan Informasi Kementerian Republik Infonesia. 2014. [cited 2016 April 30]. Available from http:// www.depkes.go.id/folder/view/01/ structure-publikasi-pusdatin-info-datin.html

2. Scully C. Medical problems in dentistry. $6^{\text {th }}$ ed. Edinburgh: Churchill Livingstone Elsevier; 2010. $573-576$.

3. Hulley SB, Cummings SR, Browner WS, Grady DG, Newman TB. Designing clinical research. 3rd ed. Philadelphia: Wolters Kluwer Lippincott Williams \& Wilkins; 2007. 65 - 93.
4. Jayakarann TG. The effect of drugs in the oral cavity - a review. J Pharm Sci \& Res. 2014; 6(2): $89-96$.

5. Razak PA, Richard KMJ, Thankachan RP, Hafiz KAA, Kumar KN, Sameer KM. Geriatric oral health: a review article. J Int Oral Health. 2014; 6(6): 110 - 116.

6. Ko-Yeh C, Katz MS, Saunders MJ. Geriatric dentistry: integral component to geriatric patient care. Taiwan Geriatrics \& Gerontology. 2008; 3(3): 182 - 192.

7. Panov JA, Krastea A. Tongue coating in patients with gastrointestinal and liver disease. J of IMAB. 2012; 18(2): 188 - 195.

8. Carda C, Lloreda NM, Salom L, Ferraris MEG, Peydro A. Structural and functional salivary disorders in type 2 diabetic patients. Med Oral Patol Oral Cir Bucal. 2006; 11: E309 - 314.

9. Gonul M, Gul U, Kaya I, Kocak O, Cakmak SK, Kilic A, Kilic S. Smoking, alcohol consumption. and denture use in patient with oral mucosal lesions. J Dermatol Case Report. 2011; 5(4): $64-68$.

10. Kaur M. Hubungan kebiasaan merokok dengan coated tongue. Dentistry E-Journal. 2013; 2(1): 32 - 38 .

11. Ghom AG. Textbook of oral medicine. New Delhi: Jaypee Brothers; 2005. 333 - 345. 